\title{
Photochemical Properties of Polyethylene Modified by Low-Molecular Organic Compounds
}

\author{
Halina KaczmareK, ${ }^{\dagger}$ Dagmara OŁdAK, and Andrzej PodgórsKI \\ Faculty of Chemistry, Nicolaus Copernicus University, Gagarin 7, 87-100 Toruń, Poland
}

(Received March 10, 2003; Accepted May 21, 2003)

\begin{abstract}
Commercial polyethylene (LDPE) was physically modified by low-molecular organic compounds for acceleration of photodegradation. Two ketones (acetophenone, benzophenone) and two aromatic chloro-derivatives (benzyl chloride and 1-chloromethyl naphthalene) in the same amounts (1\%wt) were used for PE modification. The influence of UV irradiation on thin films of doped PE was studied using Fourier transform infrared (FT-IR) and UV-vis spectroscopy. Much higher yields of photoprocesses in polyethylene (PE) containing modifiers were confirmed. Effectiveness of modifier depends on chemical structure and absorption of incident UV-radiation. The possibility of obtaining of degradable packaging films based on modified PE is suggested.

KEY WORDS Polyethylene / Polymer Modification / Photochemistry / Accelerated Degradation / Ketones / Aromatic Chloro-Derivatives /
\end{abstract}

Polyolefins are important synthetic materials because of excellent properties, well-known technology and low production cost and are widely used in many industrial and domestic fields, including outdoor applications, where photochemical stability is very important. Thus, a number of studies deal with the mechanisms and kinetics of degradation as well as stabilisation of these polymers. ${ }^{1-10}$

Recently, a new ecological problem connected with utilisation of plastic waste, appears. Most plastics based on polyolefins degrade very slowly under environmental conditions. Possibilities of recycling are limited and combustion is also problematic. A promising, safe way of reduction of plastic litter in landfills could be accelerated degradation. Therefore, scientific work has been devoted to research modifiers enhancing polymer decomposition in open-air under solar exposure or microorganism attack. ${ }^{10-16}$

This work studies the effects of low-molecular organic compounds (aromatic ketones and aromatic chloro-derivatives) on polyethylene photooxidative degradation in accelerated, laboratory conditions.

Polymers containing chromophores (i.e., groups absorbing electromagnetic radiation) undergo direct decomposition with bond dissociation upon ultraviolet. ${ }^{10,14}$ In case of polyolefins, degradation starts in weak points. This process can be also initiated by impurities. Concentrations of such structural defects or contaminations are usually very low and depend on synthesis conditions. The addition of photosensitive, unstable compounds to polymer matrix significantly changes photostability. ${ }^{14-18}$ We choose organic compounds, which absorb UV-radiation and function as photoinitiators or photosensitisers in polyethylene (PE) decomposition.

Photophysical processes include formation of excited states and energy transfer in polymer occurs without change in chemical structure. Excitation energy can be dissipated either by physical processes or may be used in chemical reactions. ${ }^{19,20}$

Photooxidative degradation of PE depends on physical state, crystallinity, starting molecular weight, defects, types of end groups, intensity of incident light, temperature and atmosphere (presence of oxygen). General mechanism of PE degradation, thermally or photocemically induced, includes chain scission, crosslinking, branching, oxidation, cyclization, and other secondary reactions. In case of PE photodegradation, free radical mechanism is usually considered. ${ }^{1,3,9,10}$ We checked if the introduction of unstable organic compounds to PE film would change the course of these processes.

\section{EXPERIMENTAL}

Commercial polyethylene (low-density PE, produced in Płock, Poland) and additives: acetophenone $(\mathrm{APh})$, benzophenone $(\mathrm{BPh})$, 1-chloromethylnaphthalene $(\mathrm{CN})$ and benzyl chloride $(\mathrm{CB})$ (analytical grade, purchased from Sigma-Aldrich Chemie GMBH) were used without any purification. Thin films were obtained by compression moulding at $200^{\circ} \mathrm{C}$ for $1 \mathrm{~min}$ using Specac press equipped with heatable plates and temperature controller unit. The films were quenched in cool press by circulating water.

Samples of the same thickness were exposed to

†To whom correspondence should be addressed (E-mail: halina@chem.uni.torun.pl). 
low-pressure mercury vapour lamp TUV30W (Philips, Holland) under room conditions $\left(25^{\circ} \mathrm{C}\right.$ and air atmosphere). The distance between sample and light source was $3 \mathrm{~cm}$. The intensity of incident light as measured by IL1400 Radiometer (International Light, USA), was $3.2 \mathrm{~mW} \mathrm{~cm}^{-2}$. Wavelength of the radiation was $254 \mathrm{~nm}$.

Absorption fourier transform infrared (FT-IR) spectra and UV-vis spectra before and after each period of exposure were carried out using FT-IR Genesis II (Mattson, USA) and UV-1601PC Spectrophotometer (Shimadzu, Japan), respectively. One hundred scans were applied for recording FT-IR spectra.

Changes in absorption of characteristic for PE bands and absorption (or integral intensity) of new bands formed by photooxidation were estimated. The spectra of starting non-exposed samples were used as references. All calculations were normalized by film thickness. The dependence of absorption change versus irradiation time was plotted for all $\mathrm{PE}$ compositions.

Two sets of the same samples were tested simultaneously to check the reproducibility of results.

\section{RESULTS AND DISCUSSION}

Electronic spectra of four organic compounds are shown in Figure 1. Absorption corresponding to $\mathrm{C}=\mathrm{O}$ in both ketones ( $\mathrm{APh}$ and $\mathrm{BPh}$ ) rapidly decreased just after $5 \mathrm{~min}$ of UV-irradiation (Figures $1 \mathrm{a}$ and $1 \mathrm{~b}$ ). Decomposition of chloroderivatives was also very efficient in the first period (10-20 $\mathrm{min}$ ) of exposure to UV (Figures $1 \mathrm{c}$ and $1 \mathrm{~d})$.

Changes in UV-vis absorption spectra of pure and PE with ketones during exposure to UV-radiation are shown in Figures 2a-2c. Pure unirradiated PE had no absorption band in 200-800 nm. During UV-exposure, absorption in whole range systematically increased without any visible maximum (Figure 2a) due to formation of chromophores. The observed increase of absorption was faster in $\mathrm{PE}$ containing additives than in $\mathrm{PE}$ alone. Absorbance at $350 \mathrm{~nm}$ was chosen for comparison of photoreactions in all samples (Figure 3). Yields were considerably higher in the presence of organic compounds added compared to pure PE. Effect caused by acetophenone is somewhat higher than in the presence of benzophenone. Comparing both chloroderivatives it was concluded that benzyl chloride accelerates this process more than 1-chloronaphthalene. The same was noted for others photoproducts absorbing at another wavelength. Two aromatic rings in modifier molecule ( $\mathrm{BPh}$ or $\mathrm{CN}$ ) may cause higher steric hindrance and make difficult interactions with polymer chains.

In infrared spectra of pure and modified PE signif- $\mathbf{a}$

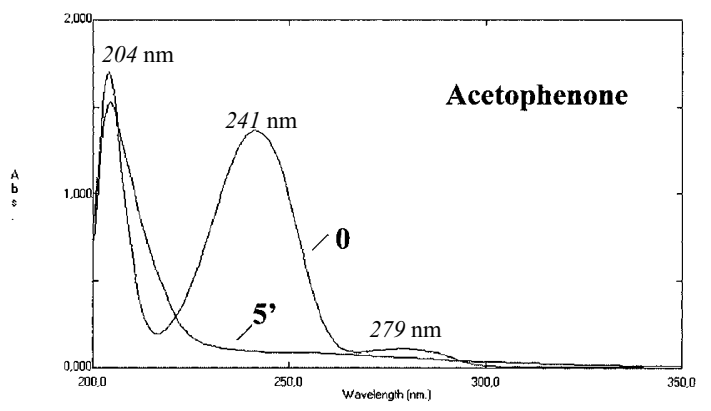

b

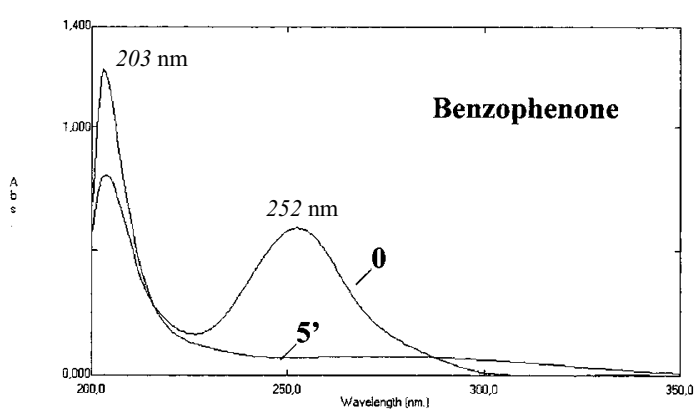

c

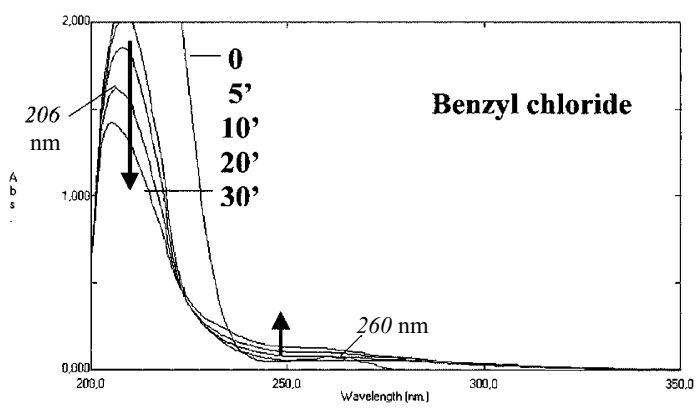

d

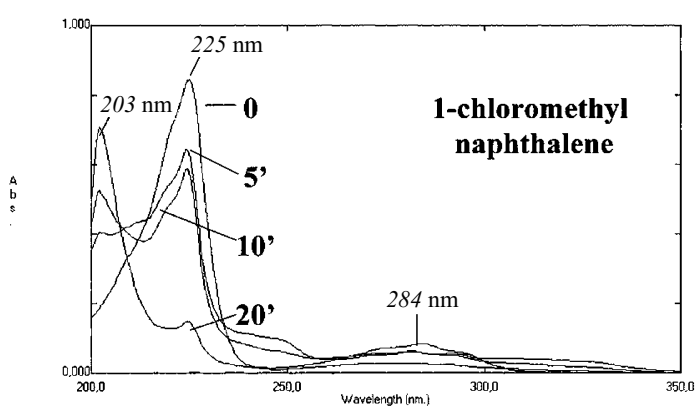

Figure 1. UV-Vis absorption spectra of acetophenone (a), benzophenone (b), benzyl chloride (c), and 1-chloromethylnaphtalene (d) before and after U-irradiation (numbers indicate the times of irradiation in minutes).

icant changes were found during UV-irradiation. Decrease of absorbance at $2700-3100 \mathrm{~cm}^{-1}$ and 1420 $1510 \mathrm{~cm}^{-1}$ region after samples exposure to UV was an evidence of PE decomposition, which is much greater in the presence of additives. An example of this for $\mathrm{PE}+1 \%$ benzyl chloride is shown in Figure 4. After $22 \mathrm{~h}$ exposure to ultraviolet, absorbance of bands 
a

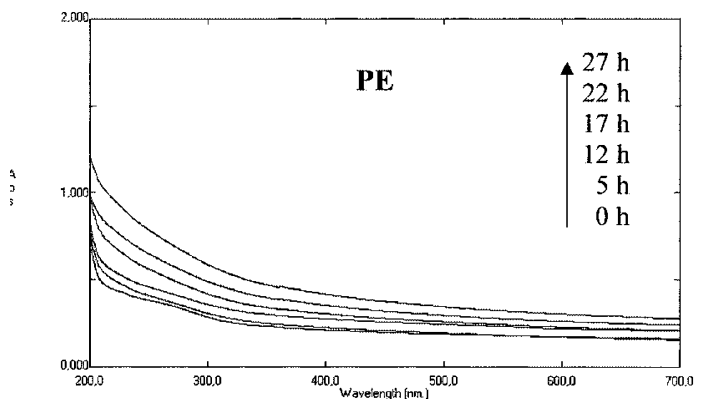

b

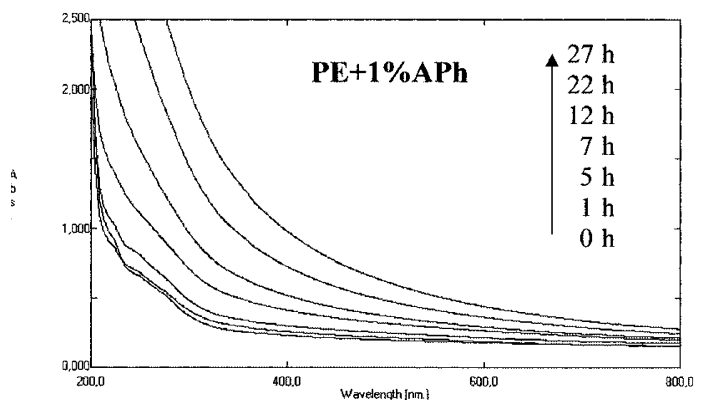

c

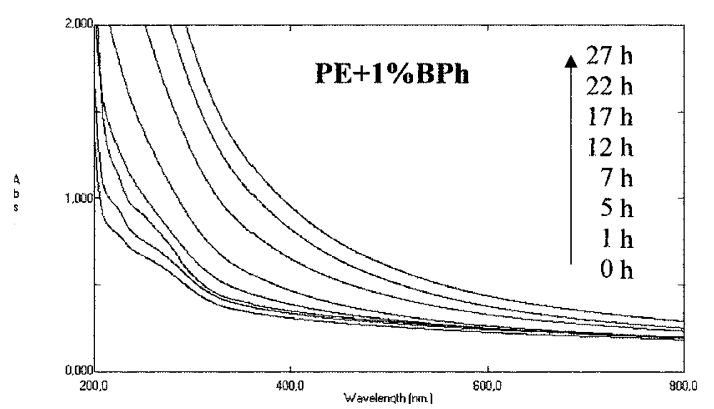

Figure 2. Changes of UV-vis absorption spectra of PE (a), $\mathrm{PE}+1 \%$ acetophenone (b), $\mathrm{PE}+1 \%$ benzophenone (c), and during UV-irradiation (numbers indicate the times of irradiation in hours).

at 2915 and $2850 \mathrm{~cm}^{-1}$ in spectrum of this sample decreased as much as $43 \%$ and $35 \%$, respectively (Figure 4a).

Figure 5 presents photodecomposition profiles (obtained by a plotting of changes of surface area at 2700 $3100 \mathrm{~cm}^{-1}$ range versus irradiation time) for all samples. The highest efficiency of PE decomposition was found for samples containing $1 \%$ benzyl chloride and chloromethylnaphthalene while in PE with ketones, was somewhat lower. The highest rate of reaction in modified PE samples was observed at the beginning of UV-irradiation $(0-5 \mathrm{~h})$. In pure $\mathrm{PE}$, an induction period was observed. Initial PE decomposition was characterised by relatively low efficiency (up to $17 \mathrm{~h}$ of exposure). Autoacceleration thus takes place contrary to modified PE's. The influence of $\mathrm{CN}$ and $\mathrm{CB}$ on PE decomposition is caused by chlorine atoms.

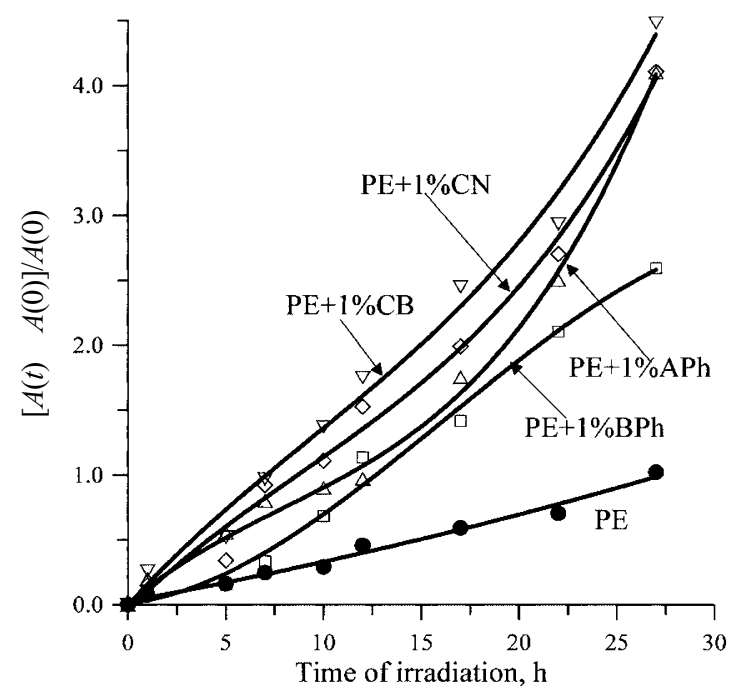

Figure 3. Dependence of chromophore content in pure and modified PE on irradiation time; $A(0)$ and $A(t)$ correspond to absorbance of the sample at $350 \mathrm{~nm}$ before and after irradiation during time $t$.

The development of carbonyl bands in all exposed samples indicated that oxidation accompanies decomposition. The bands were not very intensive but increased systematically during UV-irradiation. The broadness of carbonyl band is evidence of various oxidation products containing ketones, aldehydes, carboxylic groups, esters, peracids. ${ }^{7-10,21}$ The maximum of a carbonyl band was located at $1717 \mathrm{~cm}^{-1}$. Smaller branches were seen at 1703,1732 , and $1771 \mathrm{~cm}^{-1}$. The new low intensity band with maximum about $1650 \mathrm{~cm}^{-1}$ indicates the presence of vinylidene groups. The formation of vinyl and vinylidiene groups in UVirradiated PE (absorbing at 909 and $887 \mathrm{~cm}^{-1}$, respectively), suggested by Amin and co-workers, ${ }^{21}$ usually takes place simultaneously with carbonyl group generation. Changes in these bands were too small to quantitative calculations.

The next plot (Figure 6) shows the photooxidation of the samples. The curves were obtained from changes of integral intensity of carbonyl band (i.e., surface area under absorption band in $1580-1850 \mathrm{~cm}^{-1}$ range) plotted versus irradiation time. Rapid PE oxidation in presence of additives starts immediately upon UV radiation and the rate was highest at the first step of degradation in all samples and decreased after prolonged irradiation. At $20 \mathrm{~h}$, almost the same, constant rates for all samples are observed. Acetophenone and benzophenone exhibited the stronger acceleration effect on carbonyl group formation in PE than chloroderivatives. The efficiency of oxidation in doped PE with time was larger because of higher initial rates compared to PE without additives.

The higher influence of ketones than chloroderivatives on PE photooxidation can be explained by differ- 
a

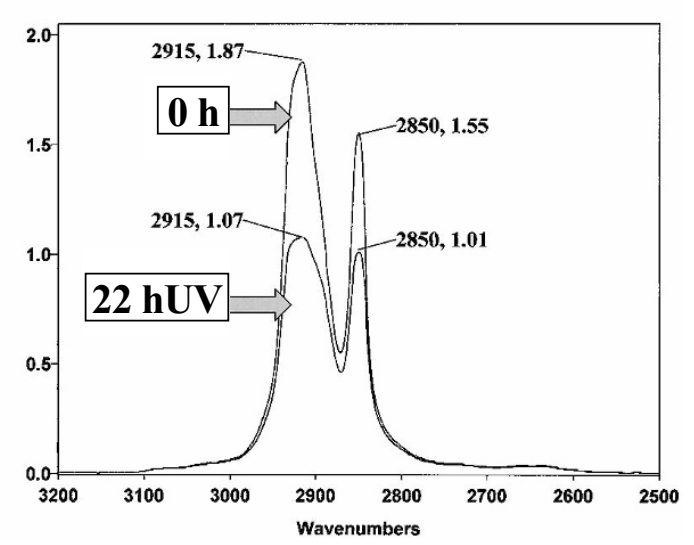

b

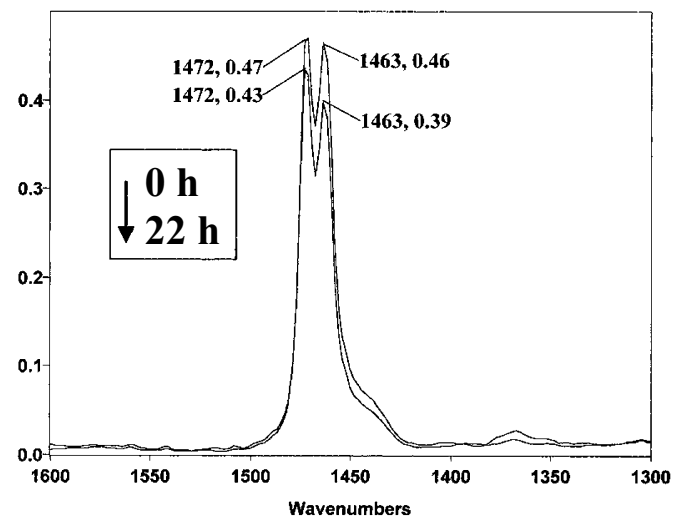

c

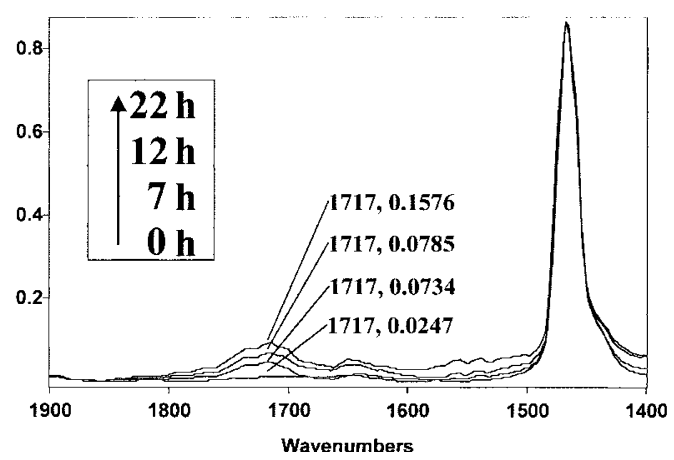

Figure 4. Changes of FT-IR spectra of PE containing $1 \%$ benzyl chloride after UV-irradiation in different regions: $\mathrm{C}-\mathrm{H}$ stretching vibrations (a), $\mathrm{C}-\mathrm{H}$ deformation vibrations (b) and carbonyl stretching vibrations (c).

ences in absorption of UV-radiation by both types of compounds. It is clearly seen in electronic spectra (Figures $1 \mathrm{a}$ and $1 \mathrm{~b}$ ) that the absorption maximum of ketones occurs at almost the same wavelength as maximum of light emitted by UV lamp $(254 \mathrm{~nm})$. However, maximum absorption of $\mathrm{CN}$ and $\mathrm{CB}$ falls in shorter wavelength (Figures 1c and 1d), and thus, overlaps the emission of light source only in small fraction.

Detailed analysis of broad band $\left(3000-3600 \mathrm{~cm}^{-1}\right)$ corresponding to hydroxyl groups was difficult because absorbance changes were very small and irregular. Probably reactions leading to $\mathrm{OH}$ groups formation

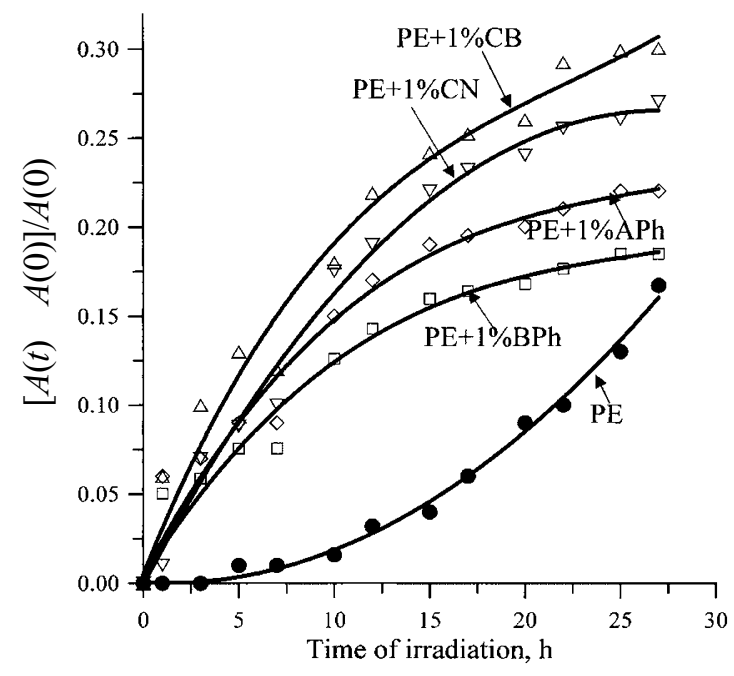

Figure 5. Photodecomposition of pure and modified PE monitored as negative change of integral intensity of $\mathrm{C}-\mathrm{H}$ versus irradiation time; $A(0)$ and $A(t)$ correspond to integral intensity of sample at $2700-3120 \mathrm{~cm}^{-1}$ before and after irradiation during time $t$.

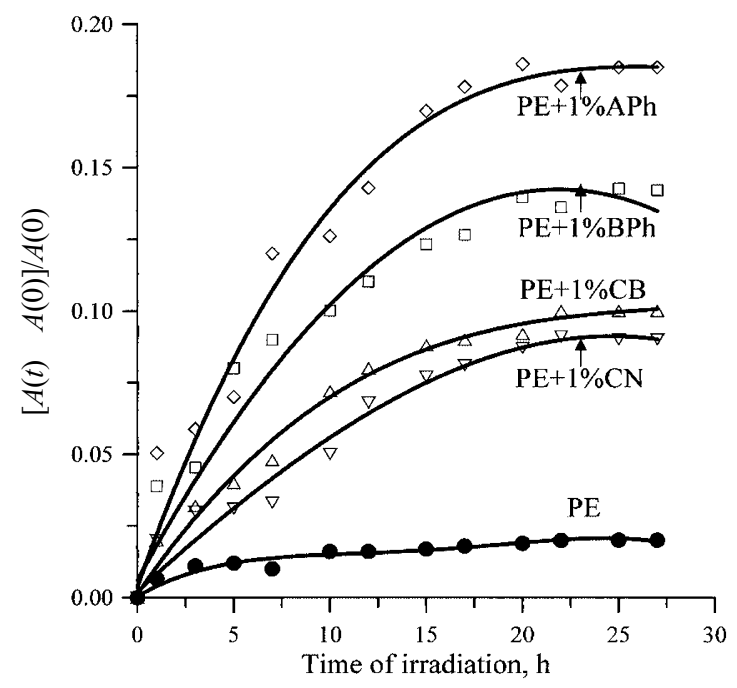

Figure 6. Photooxidation kinetics of pure and modified PE measured as changes in integral intensity of carbonyl band versus irradiation time; $A(0)$ and $A(t)$ correspond to the integral intensity of sample at $1580-1850 \mathrm{~cm}^{-1}$ before and after irradiation during time $t$.

occur with different efficiency at various periods of UVirradiation. The drop of absorption of hydroxyl band corresponds to the consumption of $\mathrm{OH} / \mathrm{OOH}$ groups in degradation. Generally, oxidation reactions leading to generation of different photoproducts (containing $\mathrm{OH}$, $\mathrm{OOH}$, or $\mathrm{C}=\mathrm{O}$ ) are competitive. The accelerating influence of organic additives was observed here. These findings confirm previous suggestion on effectiveness of compounds used as photoinitators in PE degradation. The low efficiency of carbonyl and hydroxyl groups was probably caused by cage effect. This means that macroradicals produced in polymer film recombine before reacting with oxygen. Hydroperoxides are very unstable and decompose rapidly upon UV forming mo- 
bile $\mathrm{OH}$ radicals. $\mathrm{OOH}$ groups do not accumulate on PE film in case of faster decomposition than generation and detection by FT-IR is difficult. One can conclude that ketones play a dominant role in polylefins photooxidation.

Besides of decomposition and migration of additives, some perturbation in PE photodegradation may also result from heterogeneities of film containing modifiers.

\section{Mechanism Proposed}

Absorbed UV light excites ketones to a singlet state, which quickly reverts to a triplet state by intersystem crossing (ISC): ${ }^{19,20}$

$$
\begin{aligned}
& \mathrm{R}_{1}-\stackrel{\mathrm{O}}{\mathrm{C}}-\mathrm{R}_{2} \stackrel{\mathrm{h} v}{\longrightarrow}{ }^{1}\left[\mathrm{R}_{1}-\stackrel{\mathrm{C}}{\mathrm{C}}-\mathrm{R}_{2}\right]^{*} \stackrel{\mathrm{ISC}}{\longrightarrow} 3^{\longrightarrow}\left[\begin{array}{c}
\mathrm{O} \\
\mathrm{R}_{1}-\mathrm{C}-\mathrm{R}_{2}
\end{array}\right]^{*} \\
& \text { where } \mathrm{R}_{1}=\mathrm{R}_{2}=\mathrm{C}_{6} \mathrm{H}_{5} \text { in benzophenone, } \\
& \mathrm{R}_{1}=\mathrm{CH}_{3} \text { and } \mathrm{R}_{2}=\mathrm{C}_{6} \mathrm{H}_{5} \text { in acetophenone }
\end{aligned}
$$

Ketones in triplet state may then react with macromolecules resulting to form ketyl radicals and macroradicals:

$$
\begin{aligned}
& 3\left[\begin{array}{c}
\mathrm{O} \\
\mathrm{R}
\end{array}\right. \\
& \stackrel{\mathrm{OH}}{\mathrm{R}} \mathrm{C}_{1}-\mathrm{C}-\mathrm{R}_{2}+m \mathrm{CH}_{2}-\mathrm{CH}^{m m}
\end{aligned}
$$

Excited ketones undergo photolysis by the Norrish I reaction:

$$
\left[\stackrel{\mathrm{O}}{\mathrm{R}_{1}-\mathrm{C}-\mathrm{R}_{2}}\right]^{*} \longrightarrow \stackrel{\mathrm{O}}{\mathrm{R}}{ }_{1}-\stackrel{\mathrm{C}}{\mathrm{C}} \cdot+\cdot \mathrm{R}_{2} \quad \text { or } \cdot \mathrm{R}_{1}+\stackrel{\mathrm{O}}{\mathrm{C}}-\mathrm{R}_{2}
$$

Energy of $254 \mathrm{~nm}$ radiation is high enough to break other bond in organic compounds and thus more free radicals are produced. Especially weak is the $\mathrm{C}-\mathrm{Cl}$ bond in $\mathrm{CB}$ and $\mathrm{CN}$. Photolysis of these compounds supplies very active $\mathrm{Cl}$ atoms having unpaired electrons, which easily migrate in PE film.

$$
\underset{\mathrm{R}}{\mathrm{C}} \mathrm{H}_{2} \mathrm{Cl} \stackrel{\mathrm{h} v}{\longrightarrow} \underset{\mathrm{R}}{\dot{\mathrm{C}}} \mathrm{H}_{2}+\dot{\mathrm{Cl}}
$$

where $\mathrm{R}=$ ( $)$ in benzyl chloride or $\mathrm{R}=$ (0) in

1-chloromethylnaphthalene

Initiator radicals are most likely to abstract hydrogen atoms from surrounding macromolecules to generate macroradicals.

$\mathrm{R}_{\mathrm{X}}^{\dot{ }}+{ }^{m n} \mathrm{CH}_{2}-\mathrm{CH}_{2}{ }^{n n} \longrightarrow \mathrm{R}_{\mathrm{X}} \mathrm{H}+{ }^{n n} \mathrm{CH}_{2}-\dot{\mathrm{C}} \mathrm{H}^{m n}$

where $\mathrm{R}_{\mathrm{X}}$ - any radical

For excited molecules, energy transfer to other sites in polymer matrix is possible. The excited triplet state of ketones or aromatic compounds can transfer the excess of energy to the ground state (atmospheric) oxygen producing singlet oxygen, which is know as an active polymer oxidant.

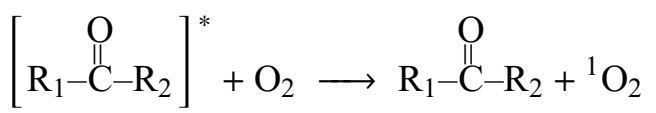

Secondary chain reactions then take place in the presence of atmospheric oxygen to produce peroxy radicals, alkoxy radicals, alkyl radicals (in chain or terminal) as well hydroperoxides, unsaturations, hydroxyl, and carbonyl groups. Besides of these reactions, main chain scission, branching, and crosslinking also take place. The oxidation products lead to further autoacceleration of PE decomposition because of absorption of light.

Radicals formed during PE irradiation undergo addition to unsaturated groups in chain. Such reactions were not observed in this study (Figure 3).

Although modifying substances disappear very fast (within few minutes) the degradation of doped PE was found to continue with prolonged UV-radiation. Active species formed during photolysis of additives (excited molecules and small free radicals) thus efficiently initiate polymer degradation, which can further occurs in macromoleules without external activator. It is known that degradation processes are chain reactions. ${ }^{1,3,10}$ The species formed at the beginning in PE oxidized groups can reinitiate its decomposition. This is repeated many times before the termination. Our results (Figures 3 and 5) show that degradation is not finished just after $30 \mathrm{~h}$ of UV-irradiation and thus initiation has great influence on propagation as well total degradation efficiency after prolonged exposure.

The behavior of thin films during UV-irradiation differs from photodegraded bulk polymer. Photochemical reactions develop mainly on the top layer of an irradiated polymer surface. The present result are thus applicable only to thin films and may be used for designing degradable packaging materials. Studies with low energetic and more selective radiation (similar to terrestrial radiation) are also necessary. The experiment conditions should be similar to the natural environment.

\section{CONCLUSIONS}

Photooxidative degradation of PE films is efficiently accelerated by introduction of $1 \%$ low-molecular, photounstable organic compounds (ketones or aromatic chloroderivatives) as shown by UV-vis and FT-IR spectroscopy analysis which allowed monitoring even very small changes in functional groups formed or disappearing during UV-irradiation of polymer.

Efficient enhancement of PE degradation and chro- 
mophores formation was observed in the presence of benzyl chloride and 1-chloromethylnaphthalene while acethophenone and benzophenone showed greater effect on PE photooxidation.

The action of ketones on PE photodegradation is caused by sensitising or initiating effect. Probably high absorption of UV irradiation by additives is necessary for acceleration of photooxidation, which suggests that energy transfer is essential. Small radicals formed during initiator photolysis have dominant roles in chain scission. Modifiers containing one phenyl groups facilitate PE degradation more than compounds with two aromatic rings in their structure.

The additives play a main role at the initial stage of PE photodegradation but formed absorbing photoproducts (ketones, hydroperoxides, double bonds, etc.) have a strong effect at further stages.

In the case of PE, even decomposition dependent on chain scission can be followed by FT-IR spectra. It is thus possible to avoid not always accessible high temperature gel permeation chromatography (GPC) or using special chromatographic solvents (very pure and expensive) or time-consuming viscometric technique.

Modified PE with enhanced photodegradability is characterised by higher susceptibility to biodegradation. Production of degradable packaging films at the base of PE doped with ketones or chloroderivatives is proposed.

Acknowledgment. Financial support by a grant No 3T09B 08818 from the Polish State Committee for Scientific Research (KBN) is gratefully acknowledged.

\section{REFERENCES}

1. N. S. Allen, "Degradation and Stabilisation of Polyolefins", Applied Science Publishers, London, 1983.

2. G. Geuskens, F. Debie, M. S. Kabamba, and G. Nedelkos, Polym. Photochem., 5, 313 (1984).

3. D. M. Wiles and D. J. Carlsson, 'New Aspects of the Photo- oxidation and Photostabilization of Polyolefins', in 'New Trends in the Photochemistry of Polymers" N. S. Allen and J. F. Rabek Ed., Elsevier Science Ltd., London, 1985, str. 147.

4. T. Czekaj, J. Appl. Polym. Sci., 32, 3299 (1986).

5. A. Torikai, S. Asada, and K. Fueki, Polym. Photochem., 7, 1 (1986).

6. A. L. Andrady, J. Appl. Polym. Sci., 39, 363 (1990).

7. J. Lemaire, R. Arnaud, Polym. Photochem., 5, 243 (1984).

8. a) F. Gugumus, Angew. Makromol. Chem., 182, 85 (1990). b) F. Gugumus, Angew. Makromol. Chem., 182, 111 (1990).

9. a) F. Gugumus, Polym. Degrad. Stab., 52, 131 (1996). b) F. Gugumus, Polym. Degrad. Stab., 52, 145 (1996). c) F. Gugumus, Polym. Degrad. Stab., 52, 159 (1996). d) F. Gugumus, Polym. Degrad. Stab., 53, 161 (1996). e) F. Gugumus, Polym. Degrad. Stab., 55, 21 (1997).

10. S. H. Hamid, Ed., "Handbook of Polymer Degradation", 2nd ed, Marcel Dekker, Inc., New York, N.Y., 2000.

11. P. B. Shah, S. Bandopadhyay, and J. R. Bellare, Polym. Degrad. Stab., 47, 165 (1995).

12. A. C. Albertsson and S. Karlsson, J. Appl. Polym. Sci., 35, 1289 (1988).

13. D. Buchowska, R. Steller, and W. Meissner, Polym. Degrad. Stab., 60, 471 (1998).

14. J. E. Guillet, in "Degradable Materials" S. A. Barenberg, J. L. Brash, R. Narayan, and A. E. Redpath, Ed., CRC Press, Boca Raton, FL., 1990.

15. G. Scott and D. Gilead, "Degradable Polymers. Principles and Applications", Chapman and Hall Ltd., London, 1995.

16. H. Kaczmarek, "Efekty przyspieszania fotochemicznego rozkładu polimerów przez substancje mało- i wielkoczạsteczkowe (The acceleration effect of low- and highmolecular substances on the photochemical destruction of polymers)", Toruń: UMK, 1998.

17. E. Mantovani, M. Mazzei, A. Robertiello, and A. Zanobi, $J$. Appl. Polym. Sci., 21, 589 (1977).

18. L. J. Taylor and J. W. Tobias, J. Appl. Polym. Sci., 26, 2917 (1981).

19. S. Paszyc, "Podstawy fotochemii (Principles of Photochemistry)", Warszawa: PWN, 1992.

20. P. Suppan, "Chemistry and light", Polish edition, Warszawa: PWN, 1997.

21. M. U. Amin, G. Scott, and L. M. K. Tillekeratne, Eur. Polym. J., 11, 85 (1975). 